\title{
A CASE REPORT OF SPLENIC HAEMANGIOMATOSIS
}

\section{S. S. Karbhari1 ${ }^{1}$ Puneeth Thalasta ${ }^{2}$, Ravindra B. Dhaded ${ }^{3}$}

1 Professor, Department of General Surgery, M. R. Medical College, Kalaburagi.

${ }^{2}$ Postgraduate Student, Department of General Surgery, M. R. Medical College, Kalaburagi.

3 Professor and HOD, Department of General Surgery, M. R. Medical College, Kalaburagi.

\begin{abstract}
\section{BACKGROUND}

Splenomegaly is the most commonly encountered clinical condition in both paediatric and adult age group and usually is associated with features of hypersplenism. Splenic neoplasm is rarely encountered, out of these small localised haemangiomas are common but isolated diffuse splenic haemangiomatosis is very rare. Case- We report a case with significant splenomegaly without any symptoms or derangement in haematological parameters caused by diffuse haemangiomatosis in a 15-year-old boy. The differential diagnosis of diffuse splenic haemangiomatosis must include the other vascular tumours or tumour-like lesions of the spleen such as lymphangioma, littoral cell angioma, haemangioendothelioma and primary angiosarcoma, peliosis of the spleen, hamartoma and traumatic cyst. We report this case of diffuse haemangiomatosis by virtue of its rareness and the presence of many other vascular lesions in the differential diagnosis.
\end{abstract}

\section{KEYWORDS}

Splenic Haemangiomatosis, Traumatic Cyst.

HOW TO CITE THIS ARTICLE: Karbhari SS, Thalasta P, Dhaded RB. A case report of splenic haemangiomatosis. J. Evolution Med. Dent. Sci. 2017;6(27):2278-2281, DOI: 10.14260/Jemds/2017/490

\section{BACKGROUND}

Splenic haemangiomas are the most common primary neoplasm of the spleen. Usually, they are asymptomatic incidental findings and can easily be diagnosed with Computed Tomography (CT) or Magnetic Resonance Imaging (MRI), due to their typical contrast enhancement. As benign tumours, haemangiomas usually do not require any treatment.1,2 Rarely, especially if localised under the splenic capsule, splenic haemangiomas can cause subcapsular haematomas, complete splenic rupture and consequently severe internal bleeding.

Haemangioma is the most common primary benign neoplasm of spleen ${ }^{3}$ and usually represents as a small, localised tumour. ${ }^{4}$ Diffuse haemangiomatosis is a variant of haemangioma and splenic parenchyma is permeated and widely replaced by vascular proliferations. This condition may occur together with haemangiomatosis of the liver or it may occur as a manifestation of systemic angiomatosis or less commonly is confined to the spleen. ${ }^{5}$ We present a case with significant splenomegaly caused by haemangiomatosis. The patient had no clinical disorders resulting from the splenic vascular tumour.

\section{CASE REPORT}

Here, we present a case of a 15-year-old boy, who was admitted with the chief complaints of mass in the left upper abdomen since 7 to 8 months, which was insidious in onset and gradually progressive. Apart from the mass in the left upper abdomen, patient did not have any other significant

Financial or Other, Competing Interest: None.

Submission 25-02-2017, Peer Review 21-03-2017,

Acceptance 27-03-2017, Published 03-04-2017.

Corresponding Author:

Dr. S. S. Karbhari,

Professor, Department of General Surgery,

M. R. Medical College, Kalaburagi.

E-mail: sharankarbhari@gmail.com

DOI: $10.14260 /$ jemds $/ 2017 / 490$

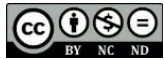

complaints. Patient also gave history of blunt trauma to the abdomen while playing 1 year back, which later on correlating with CT and MRI findings was thought to be the traumatic cyst of spleen, but histopathological examination turned out to be haemangiomatosis of the spleen.

On physical examination a large, firm, non-tender spleen extending from the costal margin to about 4 fingers below the left costal margin was noted (Figure 1). Complete blood count, coagulation and liver function tests were found to be within normal limits.

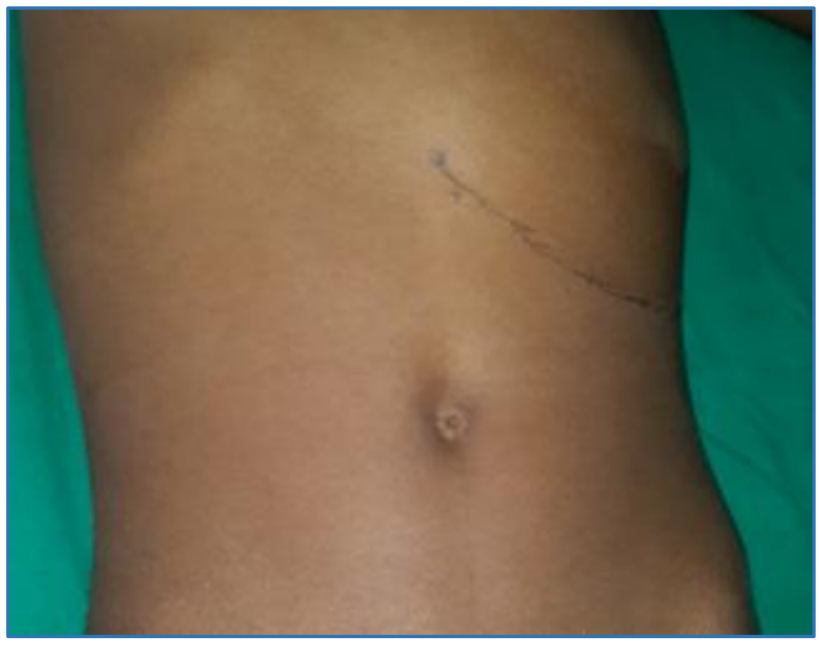

Figure 1. Showing the Enlargement of Spleen below the Left Costal Margin

Ultrasound examination of abdomen showed splenomegaly $17 \times 12 \mathrm{cms}$ with large cystic lesion measuring $14 \times 11 \mathrm{cms}$ and septations in its lower part probably pseudocyst/hydatid cyst.

CT scan showed enlarged spleen with a large hypodense lesion measuring $12 \times 10 \mathrm{cms}$ with the lesion showing few enhancing septations in its lower part with tiny calcifications in the wall of the lesion (Figure 2). 


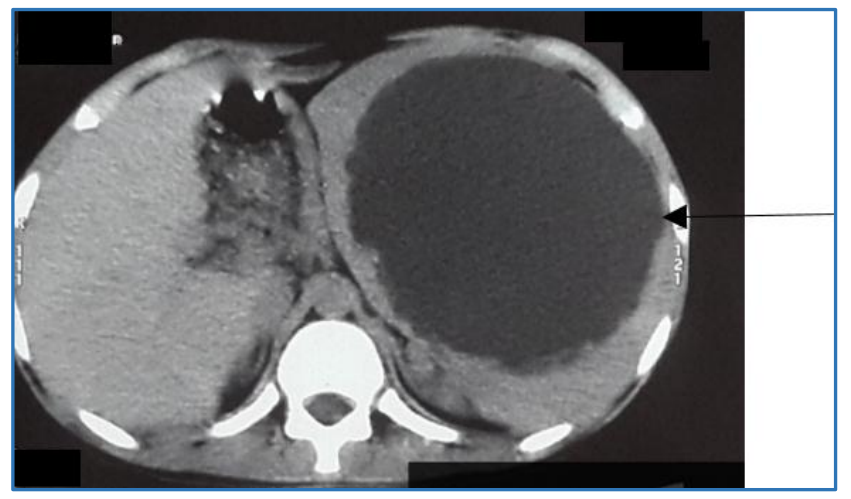

Figure 2. Showing an Enlarged Spleen with Hypodense Lesion

MRI showed spleen measuring $16 \times 12 \mathrm{~cm}$ enlarged in size with evidence of well-defined lobulated T2/STIR hyperintensity lesion measuring $14 \times 11.2 \mathrm{~cm}$ noted in the mid and lower pole of spleen with internal septations (Figure 3 and 4).

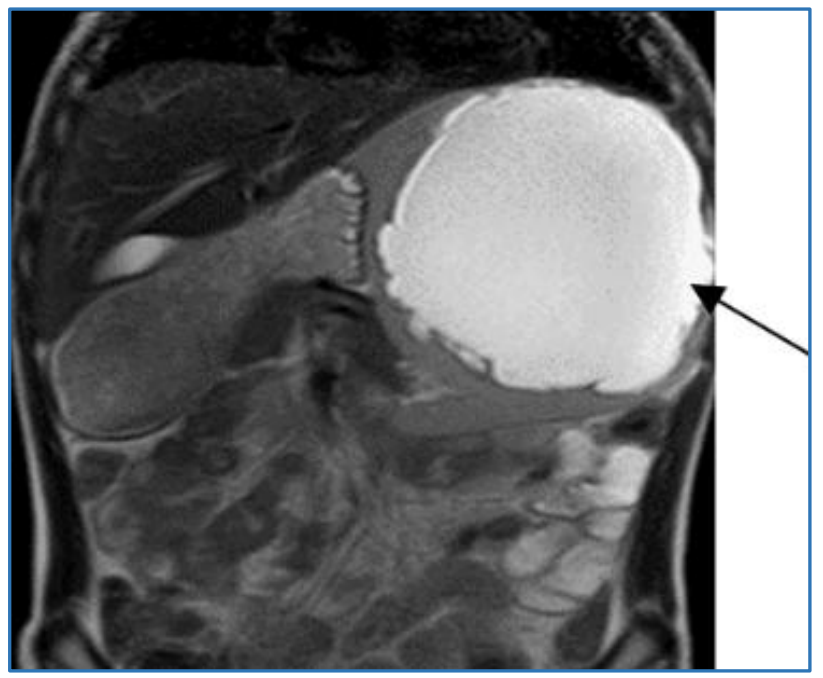

Figure 3. MRI showing Well-Defined Lobulated T2/STIR Hyperintensity Lesion

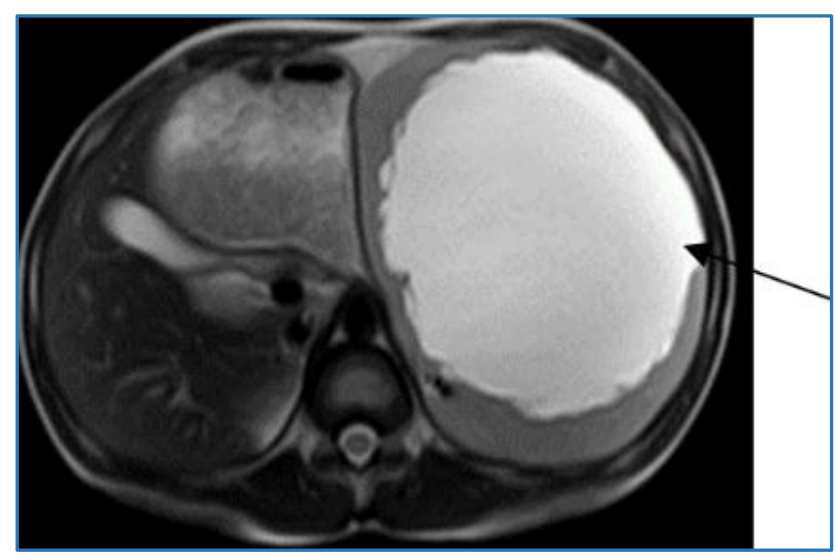

Figure 4. MRI showing Well-Defined Lobulated T2/STIR Hyperintensity Lesion

For diagnostic and therapeutic purposes, patient underwent splenectomy. Post-operative period was uneventful and the patient was given vaccinations as per splenectomy immunoprophylaxis.

\section{Gross Appearance}

A large spleen measuring $13 \times 7 \times 1.5 \mathrm{~cm}$ with cystic areas with grey white areas and focal areas of ruptured capsule measuring $3.5 \times 15 \mathrm{~cm}$ was visualised and the inner surface of cyst wall showed grey brown thick wavy fibres. (Figure 5 and 6).

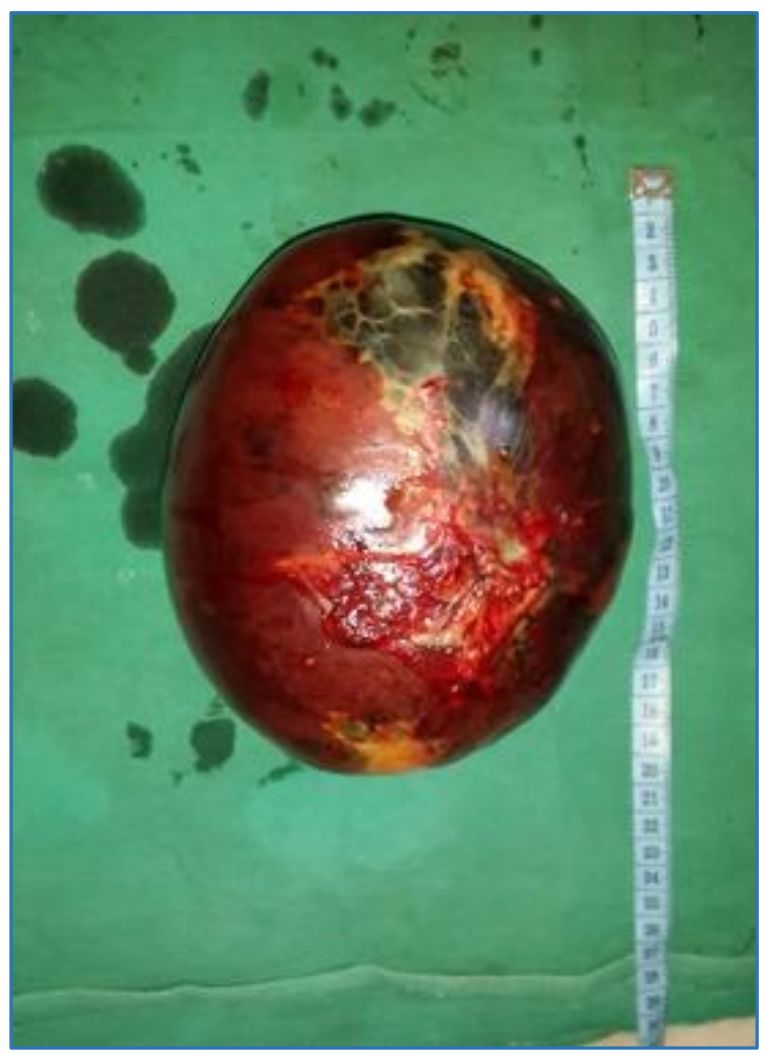

Figure 5. Gross Appearance of Splenectomy Specimen

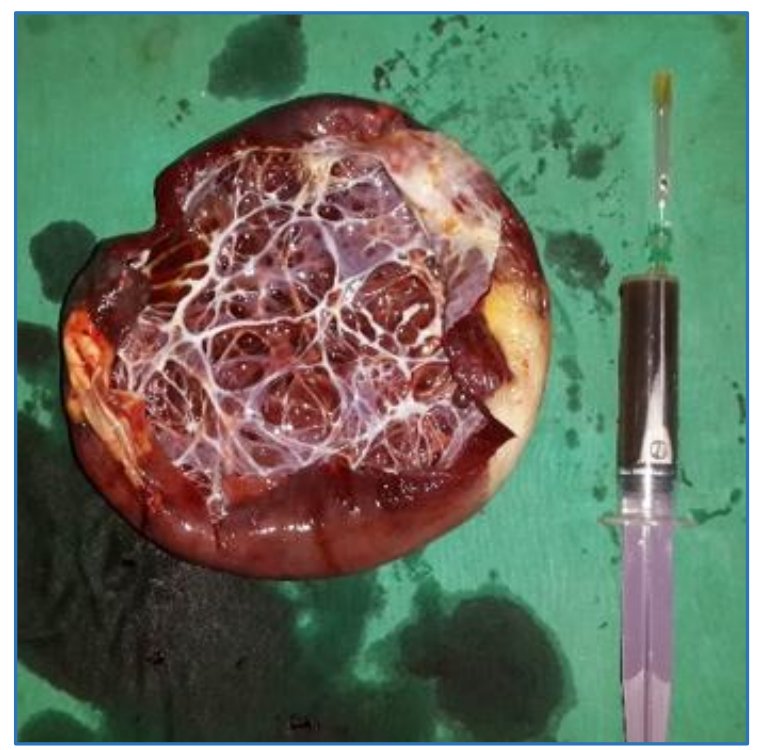

Figure 6. Cut Section of Splenectomy Specimen

\section{Microscopy}

Section studied showed capsule, white and red pulp. There was increased proliferation of vascular spaces lined by single layer of bland endothelial cells with areas of haemorrhage 
and necrosis (Figure 7). Features were consistent with haemangiomatosis of spleen.

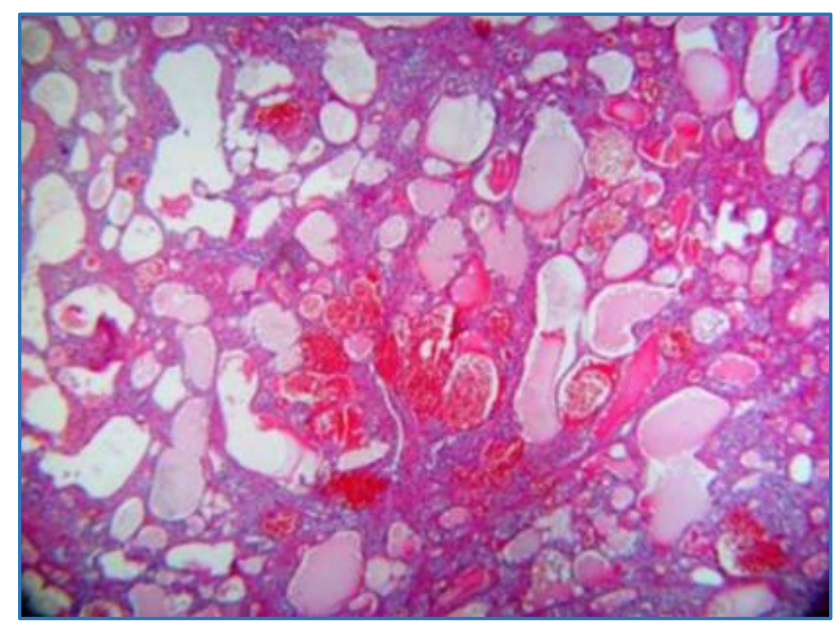

Figure 7. Histopathological Image

\section{DISCUSSION}

The spleen is a highly vascular organ composed of red pulp, which makes up the majority of the spleen and is the site of phagocytosis and white pulp, which is the lymphoid component. With these distinct components, the spleen performs a variety of functions including filtration, erythrocyte culling, platelet reservoir, haematopoiesis as well as immune surveillance and response. 6

Given its varying functions, the spleen is susceptible to a wide range of conditions: infectious and inflammatory processes, vascular and haematologic disorders, benign and malignant neoplasms (whether primary, secondary or haematolymphoid) and storage diseases. Classically, these conditions have been divided into those affecting the red pulp and those affecting the white pulp. While not perfect, these categories serve as a useful method to provide a systematic approach to splenic pathology.

Disorders predominantly affecting the white pulp include the varying causes of reactive hyperplasia (e.g. rheumatoid arthritis, immune thrombocytopenic purpura and acquired immune deficiency syndrome) as well as malignant lymphomas and related lymphoproliferative disorders (e.g. chronic lymphocytic leukaemia, large B-cell lymphoma, T-cell lymphoma and Hodgkin lymphoma). Disorders predominantly affecting the red pulp include infections (e.g. mononucleosis), congestion (e.g. haemolytic anaemia), storage disorders (e.g. Gaucher disease), leukaemia (e.g. chronic myelogenous leukaemia and hairy cell leukaemia), non-haematopoietic tumours (e.g. cysts, hamartomas, haemangiomas, lymphangiomas, littoral cell angiomas, angiosarcomas and metastases) and peliosis. ${ }^{7}$

While haemangiomas are rare, they are the most common benign primary tumour of the spleen. They can range in size from capillary to cavernous with most being cavernous type. Cavernous haemangiomas of the spleen can undergo thrombosis and infarction, resulting in the formation of central coarse calcifications. Rim calcification may also be present in the cystic spaces that compose cavernous haemangiomas. ${ }^{8}$ Splenic haemangiomatosis with diffuse replacement of the normal splenic parenchyma is even more rare and is most frequently seen in cases of diffuse angiomatosis, such as Klippel-Trenaunay syndrome. Haemangiomas of the spleen are usually asymptomatic and incidentally discovered. Patients with large haemangiomas or haemangiomatosis may experience symptoms referable to splenomegaly. Kasabach-Merritt syndrome (Anaemia, thrombocytopenia and coagulopathy) and portal hypertension have been reported in patients with haemangiomatosis of the spleen. In prior decades, $25 \%$ of patients were diagnosed with splenic haemangioma presented with acute abdominal symptoms related to rupture. ${ }^{9}$

\section{CONCLUSION}

In conclusion if there is splenic vascular proliferation, haemangiomatosis should be taken into consideration as well as lymphangioma, littoral cell angioma, haemangioendothelioma and primary angiosarcoma, peliosis of the spleen and hamartoma. In many studies, different results about the immunohistochemical phenotype of splenic vascular lesions have been reported. Further studies are needed to elucidate the importance of the immunohistochemical findings in the pathogenesis and differential diagnosis of the splenic vascular lesions.

In our case patient also gave history of blunt trauma to the abdomen while playing 1 year back, which later on correlating with CT and MRI findings was thought to be the traumatic cyst/pseudocyst of spleen, but histopathological examination turned out to be haemangiomatosis of the spleen. Hence, haemangiomatosis of spleen should also be considered in case of history and imaging findings are suggestive of traumatic/pseudocyst.

\section{REFERENCES}

[1] Steininger H, Pfofe D, Marquardt L, et al. Isolated diffuse hemangiomatosis of the spleen: case report and review of literature. Pathol Res Pract 2004;200(6):479-85.

[2] Ambrosio MR, Rocca BJ, Di Mari N, et al. Multifocal capillary hemangioma (hemangiomatosis) of the spleen. Tumori 2012;98(1):e22-6.

[3] Arber DA, Strickler JG, Chen YY, et al. Splenic vascular tumors: a histologic, immunophenotypic, and virologic study. Am J Surg Pathol 1997;21(7):827-35.

[4] Burke JS. The spleen. Sternberg's diagnostic surgical pathology. $4^{\text {th }}$ edn. Philadelphia Lippincott Williams \& Wilkins 2004:pp 849.

[5] Dufau JP, le Tourneau A, Audouin J, et al. Isolated diffuse hemangiomatosis of the spleen with KasabachMerritt-like syndrome. Histopathology 1999;35(4):337-44.

[6] Chadburn A. The spleen: anatomy and anatomical function. Semin Hematol 2000;37(1 Suppl 1):13-21.

[7] Burke JS. The spleen. In: Mills SE, (eds). Sternberg's diagnostic surgical pathology. $4^{\text {th }}$ edn. Philadelphia: Lippincott Williams \& Wilkins 2004:849-78. 


\section{Jemds.com}

[8] Abbott RM, Levy AD, Aguilera NS, et al. From the archives of the AFIP: primary vascular neoplasms of the spleen: radiologic-pathologic correlation. Radiographics 2004;24(4):1137-63.

\section{Case Report}

[9] Husni EA. The clinical course of splenic hemangioma with emphasis on spontaneous rupture. Arch Surg 1961;83:681-8. 